Western University

Scholarship@Western

$2-1-2018$

\title{
The effect of cold acclimation on active ion transport in cricket ionoregulatory tissues.
}

Lauren E Des Marteaux

Soheila Khazraeenia

Gil Y Yerushalmi

Andrew Donini

Natalia G Li

See next page for additional authors

Follow this and additional works at: https://ir.lib.uwo.ca/biologypub

Part of the Biology Commons

\section{Citation of this paper:}

Des Marteaux, Lauren E; Khazraeenia, Soheila; Yerushalmi, Gil Y; Donini, Andrew; Li, Natalia G; and Sinclair, Brent $\mathrm{J}$, "The effect of cold acclimation on active ion transport in cricket ionoregulatory tissues." (2018).

Biology Publications. 95.

https://ir.lib.uwo.ca/biologypub/95 


\section{Authors}

Lauren E Des Marteaux, Soheila Khazraeenia, Gil Y Yerushalmi, Andrew Donini, Natalia G Li, and Brent J Sinclair 
1 The effect of cold acclimation on active ion transport in cricket

2 ionoregulatory tissues

3

4 Lauren E. Des Marteaux ${ }^{a \star \dagger}$, Soheila Khazraeenia ${ }^{a}$, Gil Yerushalmi $^{\mathrm{b}}$, Andrew

5 Donini ${ }^{b}$, Natalia G. Lic, and Brent J. Sinclair ${ }^{a}$

6

7 a Department of Biology, University of Western Ontario, 1151 Richmond St., London,

8 Ontario, Canada. N6A 3K7

9 Email LED: ldesmart@uwo.ca

10 Email SK: skhazraeenia@live.com

11 Email BJS: bsincla7@uwo.ca

12

$13{ }^{\mathrm{b}}$ Department of Biology, York University, 4700 Keele St., Toronto, Ontario, Canada.

14 M3J 1P3

15 Email GY: gili@my.yorku.ca

16 Email AD: adonini@yorku.ca

17

$18{ }^{\mathrm{c}}$ Siberian Division of Russian Academy of Sciences, Lenin Ave. 41, Yakutsk, 677980, Russia

19 Email NGL: li_natalia@mail.ru

20

$21 *$ Author for correspondence

22 †Present address: Biologické centrum AV ČR, v. v. i., Branišovská 31, 37005 České

23 Budějovice, Czech Republic. tel.: +420 773060337

24 
Cold-acclimated insects defend ion and water transport function during cold exposure. We hypothesized that this is achieved via enhanced active transport. The Malpighian tubules and rectum are likely targets for such transport modifications, and recent transcriptomic studies indicate shifts in $\mathrm{Na}^{+}-\mathrm{K}^{+}$ATPase (NKA) and V-ATPase expression in these tissues following cold acclimation. Here we quantify the effect of cold acclimation (one week at $12^{\circ} \mathrm{C}$ ) on active transport in the ionoregulatory organs of adult Gryllus pennsylvanicus field crickets. We compared primary urine production of warm- and cold-acclimated crickets in excised Malpighian tubules via Ramsay assay at a range of temperatures between 4 and $25^{\circ} \mathrm{C}$. We then compared NKA and V-ATPase activities in Malpighian tubule and rectal homogenates from warm- and cold-acclimated crickets via NADH-linked photometric assays. Malpighian tubules of cold-acclimated crickets excreted fluid at lower rates at all temperatures compared to warmacclimated crickets. This reduction in Malpighian tubule excretion rates may be attributed to increased NKA activity that we observed for cold-acclimated crickets, but V-ATPase activity was unchanged. Cold acclimation had no effect on rectal NKA activity at either $21^{\circ} \mathrm{C}$ or $6^{\circ} \mathrm{C}$, and did not modify rectal V-ATPase activity. Our results suggest that an overall reduction, rather than enhancement of active transport in the Malpighian tubules allows crickets to maintain hemolymph water balance during cold exposure, and increased Malpighian tubule NKA activity may help to defend and/or re-establish ion homeostasis.

Key words: Insect, Gryllus, Malpighian tubules, rectum, sodium pump, proton pump, ion homeostasis, phenotypic plasticity 


\section{Introduction}

Chill-susceptible insects lose ion and water homeostasis at temperatures below their critical thermal minimum (the $\mathrm{CT}_{\mathrm{min}}$ ). This loss of homeostasis progresses over hours to days and appears to be driven by gradual migration of $\mathrm{Na}^{+}$down a concentration gradient from the hemolymph to the gut lumen (Coello Alvarado et al., 2015; MacMillan and Sinclair, 2011b; Overgaard and MacMillan, 2017). Water follows the migration of $\mathrm{Na}^{+}$, leading to decreased hemolymph volume and consequent increase in the concentration of hemolymph $\mathrm{K}^{+}$(in addition to $\mathrm{Mg}^{2+}$ and $\mathrm{Ca}^{2+}$ ) (Coello Alvarado et al., 2015; Des Marteaux and Sinclair, 2016; Koštál et al., 2006; MacMillan et al., 2015a; MacMillan and Sinclair, 2011b). This ionic imbalance increases the time required for insects to recover from chill coma (Findsen et al., 2013; Koštál et al., 2007; MacMillan et al., 2014; MacMillan et al., 2012), and likely contributes to the accumulation of chronic chilling injuries (Findsen et al., 2014; Koštál et al., 2006; Lee, 2010; MacMillan et al., 2015b). Defense of water and ion homeostasis during cold exposure is improved with prior mild chilling or cold acclimation (Coello Alvarado et al., 2015; Koštál et al., 2006; MacMillan et al., 2015a), but the mechanisms underlying this plasticity are not well understood.

Insects maintain water and ion balance via the Malpighian tubules (which excrete primary urine) and hindgut (across which selective reabsorption of water and ions occurs; O'Donnell and Simpson, 2008; Phillips et al., 1988). Although the primary urine is isosmotic to the hemolymph, excretion by the Malpighian tubules is dependent on ionic gradients established at the apical cell membrane by active and facilitated cation transporter (Beyenbach, 2003). Transporters include the $\mathrm{Na}^{+}-\mathrm{K}^{+}-2 \mathrm{Cl}^{-}$cotransporter $\left(\mathrm{NKCC}\right.$, which imports $\mathrm{Na}^{+}, \mathrm{K}^{+}$, and $\mathrm{Cl}^{-}$ across the basolateral cell membrane), carbonic anhydrase (CA, which provides cytosolic protons), and V-ATPase (which pumps protons to the lumen for future exchange with intracellular cations; Chintapalli et al., 2013; Coast, 2012; Halberg et al., 2015). Highly convoluted, mitochondria-dense paracellular channels in the rectal pads form the scalariform complex, in which membrane-bound $\mathrm{Na}^{+}-\mathrm{K}^{+}$ATPase (NKA) establishes a high extracellular $\left[\mathrm{Na}^{+}\right]$. This $\mathrm{Na}^{+}$concentration gradient within the rectal epithelium drives migration of water from the highly-concentrated rectal lumen to the relatively less-concentrated hemolymph (i.e. against an osmotic gradient overall). 
During cold exposure, active transport of ions across ionoregulatory epithelia is thought to be exceeded by passive leak of ions down their concentration gradients. Cold-acclimated insects are therefore expected to defend water and ion homeostasis by reducing epithelial permeability (to minimize water and ion leak) and/or by enhancing active ion transport at lower temperatures (MacMillan and Sinclair, 2011a). The latter hypothesis is supported by shifts in the transcription of genes encoding the ion pumps that drive epithelial transport in cold-acclimated Drosophila melanogaster (MacMillan et al., 2015c; MacMillan et al., 2016) and fall field crickets [Gryllus pennsylvanicus (Burmeister), Orthoptera: Gryllidae] (Des Marteaux et al., 2017). Although cold acclimation increased hindgut NKA mRNA in G. pennsylvanicus, V-ATPase mRNA in the Malpighian tubules was instead downregulated with cold acclimation. These transcriptional changes suggest that cold acclimation reduces active transport across the Malpighian tubules while enhancing active transport across the rectum.

We hypothesized that cold acclimation: 1) reduces excretion rates by decreasing Malpighian tubule V-ATPase activity, and 2) increases NKA activity in the rectum (which we expect would enhance reabsorption of $\mathrm{Na}^{+}$and water). To test these hypotheses, we compared Malpighian tubule excretion rates (a proxy for active transport) of warm- and cold-acclimated insects, and related recent findings of acclimation-attributed transcriptional changes in NKA and V-ATPase (Des Marteaux et al., 2017) to functional changes in tissue transport via enzyme activity assays in homogenized Malpighian tubules and recta. For this work we used warm- and coldacclimated G. pennsylvanicus; an emerging model system for the study of cold tolerance plasticity and its relation to water and ion homeostasis (Coello Alvarado et al., 2015; Des Marteaux and Sinclair, 2016; MacMillan and Sinclair, 2011b; MacMillan et al., 2012).

\section{Materials and methods}

\subsection{Insect rearing and acclimation}

Crickets were reared as described by Des Marteaux and Sinclair (2016). Briefly, crickets were housed in transparent $60 \mathrm{~L}$ plastic containers with stacked cardboard egg cartons for shelter, tap water, and ad libitum commercial rabbit food (Little Friends Original Rabbit Food, Martin Mills, Elmira, ON, Canada) and developed under constant summer-like conditions $\left(25^{\circ} \mathrm{C}\right.$, 14L:10D photoperiod, 70\% RH). Crickets laid eggs in containers of moist vermiculite and sterile sand which were placed at $4^{\circ} \mathrm{C}$ to accommodate an obligate three-month diapause 
116 (Rakshpal, 1962) before being returned to $25^{\circ} \mathrm{C}$ to hatch. We used adult female crickets at approximately three months post-hatch for all experiments.

Crickets were isolated in $180 \mathrm{~mL}$ transparent cups (Polar Plastics, Summit Food Distributors,

120 London, ON, Canada) with mesh fabric lids, containing egg carton shelters, rabbit food, and

121 water. Warm-acclimated crickets remained in summer-like conditions (25 $\left.{ }^{\circ} \mathrm{C}, 14 \mathrm{~L}: 10 \mathrm{D}\right)$ for the

122 week, while cold-acclimated crickets were placed in a Sanyo MIR 154 incubator (Sanyo

123 Scientific, Bensenville, Illinois) at $12^{\circ} \mathrm{C}, 10 \mathrm{~L}: 14 \mathrm{D}$ for one week. This acclimation regime

124 lowers the $\mathrm{CT}_{\min }$ (by $1.7^{\circ} \mathrm{C}$ ), speeds chill coma recovery time 3.5 -fold, and reduces the incidence of both mortality and chilling injury following chronic cold exposure (Des Marteaux et al., submitted).

\subsection{Dissections}

129 Crickets were pinned through the pronotum and the body cavity was opened by mid-dorsal 130 incision. The Malpighian tubules were removed as a bundle by detaching the ureter from the gut with forceps. The rectum was severed from the rest of the gut with microscissors. Both tissues were immediately placed in droplets of simple Ringer's solution specific to $G$. pennsylvanicus hemolymph: (in $\mathrm{mM}$ ) $110 \mathrm{Na}+, 8.5 \mathrm{~K}+, 6 \mathrm{Mg} 2+, 7 \mathrm{Ca} 2+, 144.5 \mathrm{Cl}-$, pH 7.6 (derived from Des Marteaux and Sinclair, 2016). Any adhering fat body or tracheae were removed from organs. For Ramsay assays, individual Malpighian tubules were detached from the bundle by severing with forceps as close as possible to the ampulla (where multiple tubules coalesce towards the ureter; Wall et al., 1975).

For enzyme activity assays, entire Malpighian tubule bundles were blotted on tissue paper, flash frozen in liquid nitrogen, and stored at $-80^{\circ} \mathrm{C}$ until use. Recta were cut open with microscissors to empty the lumen of fecal material, blotted on a tissue, and stored on ice for enzyme activity assays performed on the same day. Each replicate for Malpighian tubule enzyme activity assays was comprised of entire Malpighian tubule bundles pooled from five crickets. For enzyme activity assays in the recta, each replicate was comprised of pooled organs from 5-10 crickets ( $21^{\circ} \mathrm{C}$ assays) or $8-11$ crickets $\left(6^{\circ} \mathrm{C}\right.$ assay).

\subsection{Active transport across the Malpighian tubules (Ramsay assay)}

148 The rate of primary urine excretion (a proxy for active transport function) was quantified by Ramsay assay (Ramsay, 1954), using methodology modified from Rheault and O'Donnell 
150 (2004). Assays were carried out using a custom acrylic enclosure. The top surface of the 151 enclosure contained four, flat-bottomed wells $(3.5 \mathrm{~cm}$ diameter, $2.5 \mathrm{~cm}$ depth) lined with 152 Sylgard 184 (Paisley Products of Canada Inc., Scarborough, ON) and filled with paraffin oil. 153 Well temperature was monitored with type-T thermocouples connected to Picotech TC-08 154 interface and processed by PicoLog software (Pico Technology, Cambridge, UK). The 155 enclosure was connected to a refrigerated circulator (Model 1157P, VWR International, 156 Mississauga, ON, Canada) filled with a 1:1 mixture of ethylene glycol and water.

158 Four blocks $(5 \times 2.5 \mathrm{~mm})$ of Sylgard 184 were affixed to the bottom of each well in the enclosure, and a shallow incision was made by razorblade medially on the top edge of each block. A $10 \mu \mathrm{L}$ droplet of Ringer's (with $4 \mathrm{mM}$ glucose and $15 \mathrm{mM}$ HEPES added, buffered to pH 7.6) was added $3 \mathrm{~mm}$ from each block and one Malpighian tubule was placed individually into each droplet. The proximal end of each tubule was pulled from the droplet through the paraffin oil and 'cleated' into the incision on the edge of a block. The region of tubule between the droplet and block was gently punctured using a dissecting pin to produce an initial bead of primary urine. This first bead was discarded after $15 \mathrm{~min}$. Each tubule was then allowed to excrete through this puncture for $2 \mathrm{~h}$ and the diameter of each bead and the length of tubule within the droplet were measured using a microscope with an ocular micrometer. The sum of the bead diameters (assumed to be spherical) was used to calculate volume $\left(\pi \mathrm{d}^{3} / 6\right)$ excreted per hour, and corrected to the length of tubule within the droplet. Malpighian tubule excretion rate was measured at $24,16,12,8$, and $4^{\circ} \mathrm{C}(n=4,5,5,6$, and 2 crickets per treatment, respectively). The excretion rate for each cricket was the mean of the excretion rates measured from six individual Malpighian tubules.

\subsection{NKA and V-ATPase activity assays}

175 We measured NKA and V-ATPase activity in homogenates of recta and Malpighian tubules 176 from warm- and cold-acclimated crickets using an NADH-linked activity assay as described by 177 Jonusaite et al. (2011) ( $n=5$-10 per enzyme/organ/acclimation combination). Pooled tissues were diluted in $400 \mu \mathrm{L}$ in SEID buffer (in mM: 150 sucrose, 10 EDTA, 50 imidazole, and 2.5

$179 \mathrm{Na}^{+}$-deoxycholate, $\mathrm{pH}$ 7.3) and homogenized on ice for $10 \mathrm{~s}$ with a $7 \mathrm{~mm}$ attachment on a 180 Polytron PT 10-35 homogenizer (Kinetica, USA). Homogenates were centrifuged at $10000 \times g$ 181 for $10 \mathrm{~min}$ at $4^{\circ} \mathrm{C}$ and the supernatant was collected. Supernatants were diluted 5-fold further 182 with SEID for use in activity assays. A reaction buffer was comprised (in $\mathrm{mM}$ ) of $47 \mathrm{NaCl}, 2.6$ $183 \mathrm{MgCl}_{2}, 10.5 \mathrm{KCl}, 50$ imidazole, $0.27 \mathrm{NADH}, 2.6 \mathrm{ATP}$, and 2.1 phosphoenolpyruvate, with 3 
184 U.mL ${ }^{-1}$ lactate dehydrogenase (E.C. 1.1.1.27) and $3.75 \mathrm{U}^{-\mathrm{mL}^{-1}}$ pyruvate kinase (E.C. 2.7.1.40), $185 \mathrm{pH} 7.5$.

187 Duplicate wells on a 96-well plate each received $10 \mu \mathrm{L}$ of dilute supernatant and $200 \mu \mathrm{L}$ of 188 either assay buffer, assay buffer with $5 \mathrm{mM}$ ouabain (to inhibit NKA), or assay buffer with 10 $189 \mathrm{mM}$ bafilomycin A1 (to inhibit V-ATPase). NADH absorbance (at $340 \mathrm{~nm}$ ) of the reaction at $19021^{\circ} \mathrm{C}$ was then measured each minute for $30 \mathrm{~min}$ in a Multiskan Spectrum spectrophotometer 191 and SkanIt Software (v2.2) (Thermo Scientific, Wilmington, DE, USA), simultaneously for all 192 samples. Total protein concentrations of dilute sample supernatants were quantified by 193 Bradford assay against albumin standards (Kruger, 1994). Enzyme activities were calculated as 194 the difference in rates between reactions with and without enzyme inhibitors, corrected for total 195 protein abundance.

196

\subsection{Hindgut NKA activity at low temperature}

198 To determine whether cold acclimation alters rectal NKA activity during cold exposure we quantified NKA activity in homogenized recta from warm- and cold-acclimated crickets at $6^{\circ} \mathrm{C}$ using assays modified from MacMillan et al. (2015c). Briefly, recta were diluted in 14 volumes of homogenization buffer $\left(25 \mathrm{mM}\right.$ imidazole, $10 \mathrm{mM} \beta$-mercaptoethanol, $0.2 \% \mathrm{w} / \mathrm{v} \mathrm{Na}^{+}-$ deoxycholate, $\mathrm{pH}$ 7.5), homogenized with a Polytron PT 10-35, and sonicated with a Virsonic 100 (VirTis, Gardiner, NY, USA). Tissues were homogenized and sonicated each in four, $10 \mathrm{~s}$ bursts followed by $20 \mathrm{~s}$ on ice. Homogenates were then centrifuged at $7000 \times g$ for $5 \mathrm{~min}$ at $4^{\circ} \mathrm{C}$ and the supernatant was collected. Aliquots $(300 \mu \mathrm{L})$ of supernatant were filtered through a size-exclusion column (a $3 \mathrm{~mL}$ syringe barrel plugged with glass wool, containing $3 \mathrm{~mL}$ of Sephadex G50, and equilibrated with homogenization buffer) by centrifuging at $500 \times g$ for 1 min. The total protein concentrations of filtered supernatants were quantified by Bradford assay against albumin standards.

We added $10 \mu \mathrm{L}$ of filtered sample to each of four ultra-micro cuvettes; one pair of cuvettes then received $350 \mu \mathrm{L}$ of reaction buffer $\left(30 \mathrm{mM} \mathrm{KCl}, 156 \mathrm{mM} \mathrm{NaCl}, 7.8 \mathrm{mM} \mathrm{MgCl}_{2}, 74 \mathrm{mM}\right.$ imidazole, $\mathrm{pH}$ 7.5), while a second pair of cuvettes received $350 \mu \mathrm{L}$ of reaction buffer also containing $1.0 \mathrm{mM}$ ouabain. Phosphoenolpyruvate, NADH, lactate dehydrogenase, and pyruvate kinase were then added (final reaction concentrations of $4 \mathrm{mM}, 300 \mathrm{mM}, 20 \mathrm{U}_{\mathrm{mL}}^{-1}$, and $20 \mathrm{U} \cdot \mathrm{mL}^{-1}$, respectively). Reactions were initiated by adding $40 \mu \mathrm{L}$ of $50 \mathrm{mM}$ ATP in reaction buffer. 
219 NADH absorbance of each reaction was recorded five times per minute for $20 \mathrm{~min}$ at $21^{\circ} \mathrm{C}$ or $6^{\circ} \mathrm{C}(\mathrm{n}=6$ biological replicates per acclimation) in a Cary 100 Bio spectrophotometer (Varian, 221 Palo Alto, CA, USA) using WinUV Thermal Application software (v3.0, Agilent 222 Technologies). Temperature was maintained with a Cary Temperature Controller (Varian, Palo 223 Alto, CA, USA). To monitor temperature, a type-T thermocouple connected to a TC-08 224 interface was placed in a blank microvolume cuvette containing water. Enzyme activities were 225 calculated as the difference in rates between reactions with and without ouabain, corrected for total protein abundance.

\subsection{Data analyses}

229 We compared the Malpighian tubule excretion rates (Ramsay assays) of warm- and coldacclimated crickets by two-way ANOVA. Enzyme activities of warm- and cold-acclimated crickets were compared by t-tests (or Welch's t-tests when variance differed between acclimation treatments). Values reported in the text are means \pm s.e.m. All statistical analyses were performed in R (v3.3.3, R Development Core Team, 2017).

\section{Results}

\subsection{Active transport across the Malpighian tubules}

The rate of fluid excretion by the Malpighian tubules decreased with temperature $\left(F_{1,40}=102\right.$, $P<0.001)$. The $\mathrm{Q}_{10}$ s of secretion rate for warm- and cold-acclimated tubules were 2.2 and 1.9, respectively (calculated between $15.4^{\circ} \mathrm{C}$ and $24.8^{\circ} \mathrm{C}$ ). Rates of fluid excretion by coldacclimated crickets were approximately $35 \%$ slower compared to warm-acclimated crickets based on a linear model $\left(F_{1,40}=20.5, P<0.001 ;\right.$ Fig. 1$)$. We observed no significant interaction between temperature and acclimation $\left(F_{1,40}=0.046, P>0.8\right)$.

\subsection{Enzyme activities in the Malpighian tubules}

The Malpighian tubules of cold-acclimated crickets had higher NKA activity relative to warmacclimated crickets at $21^{\circ} \mathrm{C}\left(t_{15}=2.19, P=0.045\right.$; Fig. 2a). We did not observe a decrease in Malpighian tubule V-ATPase activity with cold acclimation $\left(t_{9}=1.21, P=0.26\right)$. Total protein abundance did not differ between warm- and cold-acclimated Malpighian tubules $\left(t_{24}=0.47, P\right.$ $250=0.64)$. 


\subsection{Enzyme activities in the rectum}

253 NKA activity in homogenized recta was unaffected by cold acclimation at $21^{\circ} \mathrm{C}\left(t_{15}=0.78, P\right.$ $254=0.45$; Fig. 2b). Rectal NKA activity at $6^{\circ} \mathrm{C}$ was low $(0.0094 \pm 0.0026 \mu \mathrm{mol} / \mathrm{mg} . \mathrm{min}$ and $0.0070 \pm 0.0020 \mu \mathrm{mol} / \mathrm{mg}$.min for warm- and cold-acclimated crickets, respectively) and did not differ between acclimations $\left(t_{9.4}=0.74, P=0.48\right)$. Similarly, V-ATPase activity was equivalent in the recta of warm- and cold-acclimated crickets $\left(t_{17}=1.45, P=0.16\right.$; Fig. $\left.2 b\right)$.

\section{Discussion}

We hypothesized that cold-acclimated insects should defend hemolymph volume by slowing fluid excretion rates of Malpighian tubules, and that this would be driven by a reduction in VATPase activity. Cold acclimation may have modified active transport across the Malpighian tubules, manifesting as a reduction in fluid excretion rate at both low and optimal temperatures. However, lower rates of fluid excretion were not related to modified V-ATPase activity, rather these slowed rates corresponded with an increase in NKA activity. Although we expected cold acclimation to increase rectal NKA activity (a means of enhancing water and ion reabsorption), we observed no such change at either $6^{\circ} \mathrm{C}$ or $21^{\circ} \mathrm{C}$.

\section{Cold acclimation reduces fluid excretion rates of the Malpighian tubules}

Fluid excretion by the Malpighian tubules is driven by active ion transporters, most of which are temperature-sensitive (Dietz et al., 2001; Galarza-Muñoz et al., 2011; O'Donnell and Simpson, 2008; Somero, 2004). MacMillan and Sinclair (2011a) hypothesized that cold acclimation modifies active ion transport such that ion pumping rates are maintained at lower temperatures compared to warm-acclimated insects; however, we show that the Malpighian tubules of cold-acclimated crickets excrete fluid more slowly across a range of temperatures. In Eurosta solidaginis larvae, seasonal acclimatization (between September and December) also corresponds with a reduction in the rate of Malpighian tubule transport (Yi and Lee, 2005). By reducing active transport across the Malpighian tubules, cold-acclimated orthopterans may retain hemolymph volume (i.e. mitigate leak of water) during cold exposure. However, this mechanism may not be conserved among insect lineages; in D. melanogaster, the Malpighian

282 tubules of cold-acclimated individuals instead excrete fluid more rapidly than warm-acclimated individuals (Yerushalmi et al., 2017), and knockdown of diuretic capa peptides also slows chill coma recovery (Terhzaz et al., 2015). While we expect that active transport modification is 
likely to underlie the changes in fluid excretion, it is also possible that cold acclimation reduces Malpighian tubule fluid excretion by reducing epithelial permeability (e.g. by modifying cell junctions or the expression/localization of aquaporins) (Spring et al., 2009).

Proton pumping drives net cation transport across the Malpighian tubules, and V-ATPase is central to this process (Chintapalli et al., 2013; Klein, 1992). Although V-ATPase mRNA abundance is reduced in the Malpighian tubules of cold-acclimated crickets (Des Marteaux et al., 2017), cold acclimation did not reduce the activity of this enzyme in the present study. Decreased fluid excretion rates may therefore involve modification of other enzymes (e.g. NKA or perhaps CA). Carbonic anhydrase mRNA abundance is reduced in the Malpighian tubules of cold-acclimated crickets (Des Marteaux et al., 2017), suggesting that CA is a candidate for this modification. Carbonic anhydrase in the Malpighian tubules provides protons for transport by V-ATPase and potentially the counterions $\left(\mathrm{H}^{+}\right.$and $\left.\mathrm{HCO}_{3}{ }^{-}\right)$for import of hemolymph $\mathrm{Na}^{+}$ and $\mathrm{Cl}^{-}$(Beyenbach and Piermarini, 2011; Chintapalli et al., 2013; Wessing et al., 1997). Although we did not measure CA activity in warm- and cold-acclimated crickets, decreased activity of this enzyme could drive decreased primary urine excretion in cold-acclimated crickets. Because CA is a thermally-insensitive enzyme (Feller and Gerday, 1997), cold exposure alone would not be expected to reduce activity.

Cold acclimation increased Malpighian tubule NKA activity, and this should have multiple effects on water and ion balance in the hemolymph. NKA activity in the Malpighian tubules appears to be antidiuretic; in Rhodnius, ouabain (an inhibitor of NKA) stimulates transport of $\mathrm{Na}^{+}$and fluid to the Malpighian tubule lumen (Maddrell and Overton, 1988), and the diuretic hormone 5-HT inhibits NKA activity (Grieco and Lopes, 1997). It is proposed that NKA inhibition leads to the accumulation of intracellular $\mathrm{Na}^{+}$, favoring transport of $\mathrm{Na}^{+}$and water to the lumen (Caruso-Neves and Lopes, 2000). Increased NKA activity in the Malpighian tubules of cold-acclimated crickets could therefore account in part for the decreased primary urine production rate. NKA activity in the Malpighian tubules also regulates selectivity of excreted cations. For example, inhibition of NKA by ouabain increases the $\mathrm{Na}^{+}: \mathrm{K}^{+}$ratio of the primary urine in Acheta domesticus crickets (Coast, 2012). Under optimal temperatures (e.g. $21^{\circ} \mathrm{C}$ ), increased Malpighian tubule NKA in cold-acclimated crickets may thereby hasten the removal of $\mathrm{K}^{+}$and re-establish low hemolymph $\left[\mathrm{K}^{+}\right]$during recovery from cold exposure (Beyenbach, 2003). As we would predict, chill-tolerant Drosophila spp. Also excrete primary urine with lower $\mathrm{Na}^{+}: \mathrm{K}^{+}$ratios compared to chill-susceptible species (MacMillan et al., 2015a). Although 
we did not measure Malpighian tubule enzyme activities at low temperatures, enhanced NKA activity during cold exposure could prevent or delay imbalance of hemolymph $\mathrm{Na}^{+}$, water, and $\mathrm{K}^{+}$during chill coma (both reducing the CCRT and the energetic costs of re-establishing ionic and osmotic gradients; MacMillan et al., 2012).

\section{Rectal NKA and V-ATPase activities are unchanged by cold acclimation}

Because cold exposure results in leak of $\mathrm{Na}^{+}$and water towards the gut, an obvious hypothesis is that cold acclimation enhances the activity of rectal pad NKA to mitigate this leak. Increased rectal NKA activity at higher temperatures (i.e. during rewarming) should also speed up reestablishment of $\mathrm{Na}^{+}$and water balance thereby reducing chill coma recovery time. An increase in hindgut NKA transcript abundance for cold-acclimated G. pennsylvanicus (Des Marteaux et al., 2017) certainly supports this hypothesis. However, we found no evidence of increased rectal NKA activity at $6^{\circ} \mathrm{C}$ or $21^{\circ} \mathrm{C}$. Similarly, although rectal V-ATPase transcript abundance decreases in cold-acclimated G. pennsylvanicus (Des Marteaux et al., 2017), V-ATPase activity in rectal homogenates was unchanged by cold acclimation in the present study. The significance of altered NKA and V-ATPase transcript abundance in cold-acclimated G. pennsylvanicus therefore remains in question, and further illustrates the point that mRNA abundance does not necessarily reflect increased enzyme abundance (Gygi et al., 1999).

Other enzymes controlling reabsorption across the rectum could be modified by cold acclimation, however many remain to be identified (Chintapalli et al., 2013; O'Donnell and Simpson, 2008). This poses a challenge for predicting how modification of hindgut water or ion transporters may affect transport in the cold. First, active transport across the rectal pads of warm- and cold-acclimated insects should be compared (e.g. via Ussing chamber; Ussing and Zerahn, 1951; Clarke, 2009 or everted-sac technique (Barthe et al., 1998; Lechleitner et al., 1989) to determine whether rectal transport is modified by cold acclimation overall. The specific enzymatic targets of cold acclimation (and their relative contribution to altered transport function) could then be determined by comparing active transport rates across the rectum with and without selective enzyme inhibitors (Bertram et al., 1991; Clarke, 2009; Hanrahan et al., 1984).

\section{An organ-specific role for NKA in cold acclimation?} melanogaster (MacMillan et al., 2015c) and goldenrod gall fly larvae (Eurosta solidaginis) 
353 (McMullen and Storey, 2008). However, the functional significance of modified active 354 transport should depend on the specific enzyme and organ in which that modification occurs. 355 In the Malpighian tubules of cold-acclimated G. pennsylvanicus we instead observed increased 356 NKA activity, and this should prevent loss of hemolymph volume during cold exposure. It is 357 possible that cold acclimation modifies transport function differently in dipterans than in 358 orthopterans, but we suspect that this contrast is because NKA is ubiquitously expressed and 359 comparisons of whole-body NKA activity are not informative for predicting how cold 360 acclimation affects transport function in specific ionoregulatory organs.

Changes in total protein abundance could not explain increased Malpighian tubule NKA activity, but we did not measure NKA abundance specifically. It is also possible that the abundance of NKA increases proportionally with decreased abundance of other enzymes (e.g. $\mathrm{V}$-ATPase) such that total protein abundance is unaffected. Alternately, cold-acclimated crickets could express NKA isozymes with different activities or thermal sensitivities (Blanco, 2005; Galarza-Muñoz et al., 2011). NKA activity could also be altered by changes in membrane fluidity \{Koštál, 1998 \#516\}, post-transcriptional modifications (e.g. via RNA editing; Colina et al., 2010) or by post-translational modifications (e.g. phosphorylation or dephosphorylation; McMullen and Storey, 2008; Poulsen et al., 2010; Seo and Lee, 2004). Kinase-mediated phosphorylation is already proposed to reduce NKA activity in overwintering goldenrod gall flies (McMullen and Storey, 2008). However, we do not know the extent to which these modifications persist under present assay conditions. Enzyme activity assays for homogenates are also unlikely to capture differences based on modified recruitment of enzymes to the membrane or modified cytoskeletal structure (Khurana, 2000; Lai and Jan, 2006). A first step may be to determine the effect of cold acclimation on the phosphorylation state of target ion transporters (Pavlides et al., 2011).

\section{Conclusions}

Cold acclimation reduces fluid excretion rates of Malpighian tubules, suggesting an overall reduction in active transport across the insect Malpighian tubules. Decreased excretion rates were not attributed to a reduction in V-ATPase activity (as predicted by transcriptomic changes), but may in part result from increased Malpighian tubule NKA activity. Rectal NKA activity was unchanged by cold acclimation (also contrary to observations of increased hindgut NKA transcript abundance). Modification of Malpighian tubule transport is therefore an 
387 important aspect of acquired cold tolerance; by reducing primary urine production, cold388 acclimated crickets should mitigate loss of hemolymph volume at low temperatures. Upon 389 rewarming, enhanced NKA activity should allow cold-acclimated insects to re-establish ion 390 balance more rapidly by preferentially retaining hemolymph $\mathrm{Na}^{+}$content and excreting 391 hemolymph $\mathrm{K}^{+}$.

\section{Acknowledgements}

395 We would like to thank Mike O'Donnell for training in Ramsay assays and Heath MacMillan, 396 Morag Dick, Chris Guglielmo, James Staples, and Kate Mathers for assistance with enzyme 397 assays. We also thank Michelle Lim, Nicole Kenny, Johnny Jiang, Dina Sertovic, and Huda Al398 Sharafi for assistance with insect rearing. This research was supported by the Natural Sciences 399 and Engineering Research Council of Canada (NSERC) via Canada Graduate Scholarships to 400 LED and GY, and NSERC Discovery Grants to BJS and AD and York University through a 401 Vernon Stong Scholarship to GY.

402 
Barthe, L., Woodley, J.F., Kenworthy, S., Houin, G., 1998. An improved everted gut sac as a simple and accurate technique to measure paracellular transport across the small intestine. Eur. J. Drug Metab. Pharmacokinet. 23, 313-323. Bertram, G., Schleithoff, L., Zimmermann, P., Wessing, A., 1991. Bafilomycin A 1 is a potent inhibitor of urine formation by Malpighian tubules of Drosophila hydei: is a vacuolar-type ATPase involved in ion and fluid secretion? J. Insect Physiol. 37, 201-209.

Beyenbach, K.W., 2003. Transport mechanisms of diuresis in Malpighian tubules of insects. J. Exp. Biol. 206, 3845-3856.

Beyenbach, K.W., Piermarini, P.M., 2011. Transcellular and paracellular pathways of transepithelial fluid secretion in Malpighian (renal) tubules of the yellow fever mosquito Aedes aegypti. Acta Physiologica 202, 387-407.

Blanco, G., 2005. Na, K-ATPase subunit heterogeneity as a mechanism for tissue-specific ion regulation, Seminars in Nephrology. Elsevier, 292-303.

Caruso-Neves, C., Lopes, A.G., 2000. Sodium pumps in the Malpighian tubule of Rhodnius sp. An. Acad. Bras. Cienc. 72, 407-412.

Chintapalli, V.R., Wang, J., Herzyk, P., Davies, S.A., Dow, J.A., 2013. Data-mining the FlyAtlas online resource to identify core functional motifs across transporting epithelia. BMC Genomics 14, 1. Clarke, L.L., 2009. A guide to Ussing chamber studies of mouse intestine. Am. J. Physiol. 296, G1151G1166.

Coast, G.M., 2012. Intracellular $\mathrm{Na}^{+}, \mathrm{K}^{+}$and $\mathrm{Cl}^{-}$activities in Acheta domesticus Malpighian tubules and the response to a diuretic kinin neuropeptide. J. Exp. Biol. 215, 2774-2785.

Coello Alvarado, L.E., MacMillan, H.A., Sinclair, B.J., 2015. Chill-tolerant Gryllus crickets maintain ion balance at low temperatures. J. Insect Physiol. 77, 15-25.

Colina, C., Palavicini, J.P., Srikumar, D., Holmgren, M., Rosenthal, J.J.C., 2010. Regulation of $\mathrm{Na}^{+} / \mathrm{K}^{+}$ ATPase transport velocity by RNA editing. PLoS Biol. 8, e1000540.

Des Marteaux, L.E., McKinnon, A.H., Udaka, H., Toxopeus, J., Sinclair, B., 2017. Effects of coldacclimation on gene expression in Fall field cricket (Gryllus pennsylvanicus) ionoregulatory tissues. BMC Genomics 18.

Des Marteaux, L.E., Sinclair, B.J., 2016. Ion and water balance in Gryllus crickets during the first twelve hours of cold exposure. J. Insect Physiol. 89, 19-27.

Dietz, K.-J., Tavakoli, N., Kluge, C., Mimura, T., Sharma, S., Harris, G., Chardonnens, A., Golldack, D., 2001. Significance of the V-type ATPase for the adaptation to stressful growth conditions and its regulation on the molecular and biochemical level. J. Exp. Bot. 52, 1969-1980.

Findsen, A., Andersen, J.L., Calderon, S., Overgaard, J., 2013. Rapid cold hardening improves recovery of ion homeostasis and chill coma recovery time in the migratory locust, Locusta migratoria. J. Exp. Biol. 216, 1630-1637.

Findsen, A., Pedersen, T.H., Petersen, A.G., Nielsen, O.B., Overgaard, J., 2014. Why do insects enter and recover from chill coma? Low temperature and high extracellular potassium compromise muscle function in Locusta migratoria. J. Exp. Biol. 217, 1297-1306.

Galarza-Muñoz, G., Soto-Morales, S.I., Holmgren, M., Rosenthal, J.J., 2011. Physiological adaptation of an Antarctic $\mathrm{Na}^{+} / \mathrm{K}^{+}-$ATPase to the cold. J. Exp. Biol. 214, 2164-2174.

Grieco, M.A.B., Lopes, A.G., 1997. 5-hydroxytryptamine regulates the $\left(\mathrm{Na}^{+}+\mathrm{K}^{+}\right)$ATPase activity in Malpighian tubules of Rhodnius prolixus: evidence for involvement of G-protein and cAMPdependent protein kinase. Arch. Insect Biochem. Physiol. 36, 203-214.

Gygi, S.P., Rochon, Y., Franza, B.R., Aebersold, R., 1999. Correlation between protein and mRNA abundance in yeast. Mol. Cell. Biol. 19, 1720-1730.

Halberg, K.A., Terhzaz, S., Cabrero, P., Davies, S.A., Dow, J.A., 2015. Tracing the evolutionary origins of insect renal function. Nature Communications 6. 
Hanrahan, J., Meredith, J., Phillips, J., Brandys, D., 1984. Methods for the study of transport and control in insect hindgut, Measurement of Ion Transport and Metabolic Rate in Insects. Springer, 1967.

Jonusaite, S., Kelly, S.P., Donini, A., 2011. The physiological response of larval Chironomus riparius (Meigen) to abrupt brackish water exposure. Journal of Comparative Physiology B 181, 343-352. Khurana, S., 2000. Role of actin cytoskeleton in regulation of ion transport: examples from epithelial cells. The Journal of Membrane Biology 178, 73-87. Klein, U., 1992. The insect V-ATPase, a plasma membrane proton pump energizing secondary active transport: immunological evidence for the occurrence of a V-ATPase in insect ion-transporting epithelia. J. Exp. Biol. 172, 345-354. Koštál, V., Renault, D., Mehrabianová, A., Bastl, J., 2007. Insect cold tolerance and repair of chillinjury at fluctuating thermal regimes: role of ion homeostasis. Comparative Biochemistry and Physiology A 147, 231-238.

Koštál, V., Simek, P., 1998. Changes in fatty acid composition of phospholipids and triacylglycerols after cold-acclimation of an aestivating insect prepupa. Journal of Comparative Physiology B 168, 453-460.

Koštál, V., Yanagimoto, M., Bastl, J., 2006. Chilling-injury and disturbance of ion homeostasis in the coxal muscle of the tropical cockroach (Nauphoeta cinerea). Comp Biochem Phys B 143, 171-179. Lai, H.C., Jan, L.Y., 2006. The distribution and targeting of neuronal voltage-gated ion channels. Nat. Rev. Neurosci. 7, 548-562.

Lam, R.S., Shaw, A.R., Duszyk, M., 2004. Membrane cholesterol content modulates activation of BK channels in colonic epithelia. Biochim. Biophys. Acta 1667, 241-248.

Lechleitner, R., Audsley, N., Phillips, J., 1989. Composition of fluid transported by locust ileum: influence of natural stimulants and luminal ion ratios. Can. J. Zool. 67, 2662-2668.

Lee, R.E.J., 2010. A primer on insect cold-tolerance, in: D.L. Denlinger, R.E.J. Lee (Eds.), Low Temperature Biology of Insects. Cambridge University Press.

MacMillan, H.A., Andersen, J.L., Davies, S.A., Overgaard, J., 2015a. The capacity to maintain ion and water homeostasis underlies interspecific variation in Drosophila cold tolerance. Scientific Reports 5. MacMillan, H.A., Baatrup, E., Overgaard, J., 2015b. Concurrent effects of cold and hyperkalaemia cause insect chilling injury, Proceedings of the Royal Society B, 20151483.

MacMillan, H.A., Ferguson, L.V., Nicolai, A., Donini, A., Staples, J.F., Sinclair, B.J., 2015c. Parallel ionoregulatory adjustments underlie phenotypic plasticity and evolution of Drosophila cold tolerance. J. Exp. Biol. 112, 2882-2887.

MacMillan, H.A., Findsen, A., Pedersen, T.H., Overgaard, J., 2014. Cold-induced depolarization of insect muscle: differing roles of extracellular $\mathrm{K}^{+}$during acute and chronic chilling. J. Exp. Biol. 217, 2930-2938.

MacMillan, H.A., Knee, J.M., Dennis, A.B., Udaka, H., Marshall, K.E., Merritt, T.J., Sinclair, B.J., 2016. Cold acclimation wholly reorganizes the Drosophila melanogaster transcriptome and metabolome. Scientific Reports 6.

MacMillan, H.A., Sinclair, B.J., 2011a. Mechanisms underlying insect chill-coma. J. Insect Physiol. 57, 12-20.

MacMillan, H.A., Sinclair, B.J., 2011b. The role of the gut in insect chilling injury: cold-induced disruption of osmoregulation in the fall field cricket, Gryllus pennsy/vanicus. J. Exp. Biol. 214, 726734.

MacMillan, H.A., Williams, C.M., Staples, J.F., Sinclair, B.J., 2012. Reestablishment of ion homeostasis during chill-coma recovery in the cricket Gryllus pennsy/vanicus. PNAS 109, 20750-20755.

Maddrell, S.H., Overton, J.A., 1988. Stimulation of sodium transport and fluid secretion by ouabain in an insect Malpighian tubule. J. Exp. Biol. 137, 265-276.

McMullen, D.C., Storey, K.B., 2008. Suppression of $\mathrm{Na}^{+} \mathrm{K}^{+}$-ATPase activity by reversible phosphorylation over the winter in a freeze-tolerant insect. J. Insect Physiol. 54, 1023-1027. 
Overgaard, J., MacMillan, H.A., 2017. The integrative physiology of insect chill tolerance. Annu. Rev. Physiol. 79, 187-208.

Pavlides, S.C., Pavlides, S.A., Tammariello, S.P., 2011. Proteomic and phosphoproteomic profiling during diapause entrance in the flesh fly, Sarcophaga crassipalpis. Journal of Insect Physiology 57, 509 635-644.

510 Phillips, J., Audsley, N., Lechleitner, R., Thomson, B., Meredith, J., Chamberlin, M., 1988. Some major transport mechanisms of insect absorptive epithelia. Comparative Biochemistry and Physiology A 90, 643-650.

Poulsen, H., Morth, P., Egebjerg, J., Nissen, P., 2010. Phosphorylation of the $\mathrm{Na}^{+}, \mathrm{K}^{+}-\mathrm{ATPase}$ and the $\mathrm{H}^{+}, \mathrm{K}^{+}$-ATPase. FEBS Lett. 584, 2589-2595.

Rakshpal, R., 1962. Diapause in the eggs of Gryllus pennsylvanicus Burmeister (Orthoptera: Gryllidae). Can. J. Zool. 40, 179-194. morosus (Orthoptera, Phasmidae). J. Exp. Biol. 31, 104-113. melanogaster: application of two novel electrophysiological methods. J. Exp. Biol. 207, 2173-2184. Seo, J., Lee, K.-J., 2004. Post-translational modifications and their biological functions: proteomic analysis and systematic approaches. J. Biochem. Mol. Biol. 37, 35-44. Somero, G.N., 2004. Adaptation of enzymes to temperature: searching for basic "strategies". Comp Biochem Phys B 139, 321-333.

Spring, J.H., Robichaux, S.R., Hamlin, J.A., 2009. The role of aquaporins in excretion in insects. J. Exp. Biol. 212, 358-362.

Terhzaz, S., Teets, N.M., Cabrero, P., Henderson, L., Ritchie, M.G., Nachman, R.J., Dow, J.A., Denlinger, D.L., Davies, S.-A., 2015. Insect capa neuropeptides impact desiccation and cold tolerance. PNAS 112, 2882-2887.

530 Wall, B.J., Oschman, J.L., Schmidt, B.A., 1975. Morphology and function of Malpighian tubules and associated structures in the cockroach, Periplaneta americana. J. Morphol. 146, 265-306. Wessing, A., Zierold, K., Bertram, G., 1997. Carbonic anhydrase supports electrolyte transport in Drosophila Malpighian tubules. Evidence by X-ray microanalysis of cryosections. J. Insect Physiol. 43, 17-28. Yerushalmi, G., MacMillan, H., Donini, A., 2017. Do ion-motive pumps contribute to cold-acclimation in Drosophila? The FASEB Journal 31, 719.717. 


\section{Figure captions}

543 Figure 1. Effect of cold acclimation on fluid excretion rate by the Malpighian tubules in

544 adult G. pennsylvanicus crickets. Fluid excretion was measured on isolated tubules using the 545 Ramsay assay ( $\mathrm{n}=12$ to 36 tubules per temperature-acclimation combination). The effects of 546 assay temperature and acclimation on excretion rate were both significant according to two547 way ANOVA (see text for statistics). Trend lines represent linear models for each acclimation 548 treatment.

550 Figure 2. Effect of cold acclimation on the activity of $\mathrm{Na}^{+}-\mathrm{K}^{+}$ATPase (NKA) and V551 ATPase in homogenized Malpighian tubules (A) and recta (B) of G. pennsylvanicus 552 crickets. Activity rates were measured at $21^{\circ} \mathrm{C}$ via NADH-linked assays, and given as moles 553 of ADP converted per hour (corrected for protein concentration in homogenates). Replication 554 for pooled warm- and cold-acclimated Malpighian tubule homogenates was 10 and 7 (NKA) 555 and 6 and 5 (V-ATPase), respectively. Replication for pooled warm- and cold-acclimated rectal 556 homogenates was 8 and 9 (NKA) and 9 and 10 (V-ATPase), respectively. Significant 557 differences in the activity of a given enzyme between warm- and cold-acclimated tissues is 558 represented by an asterisk. 


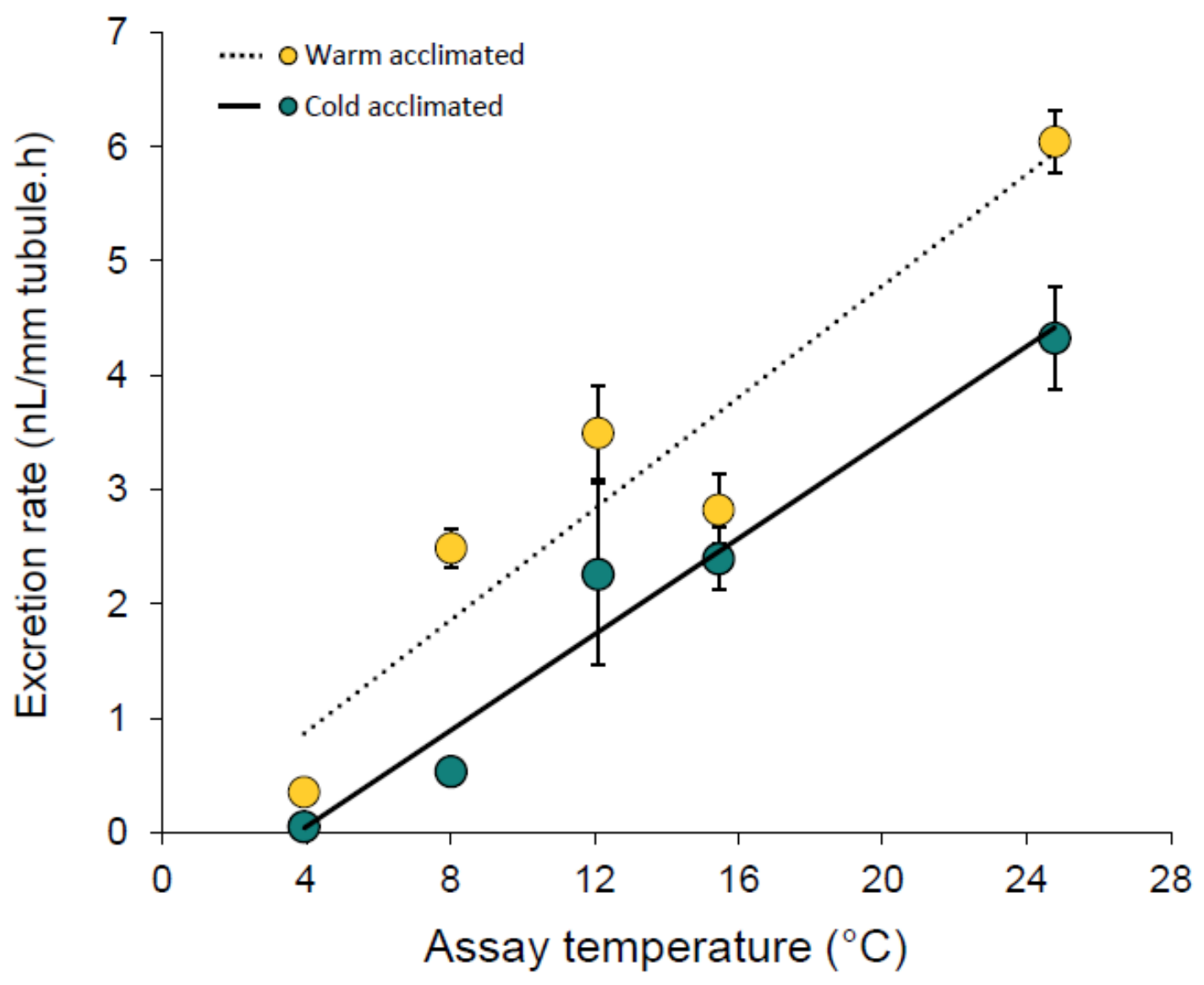

Figure 1 
A. Malpighian tubules

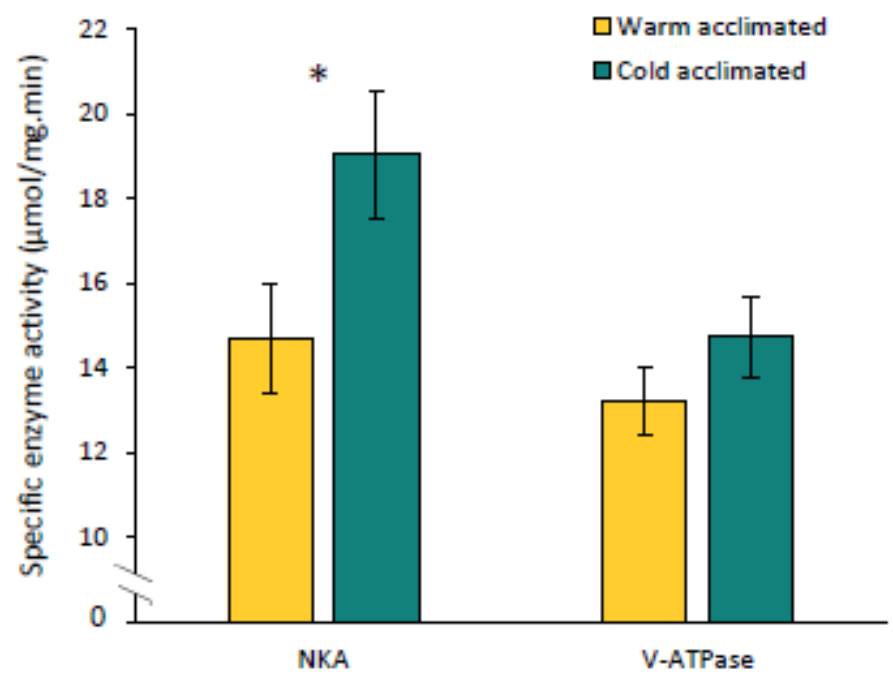

B. Recta

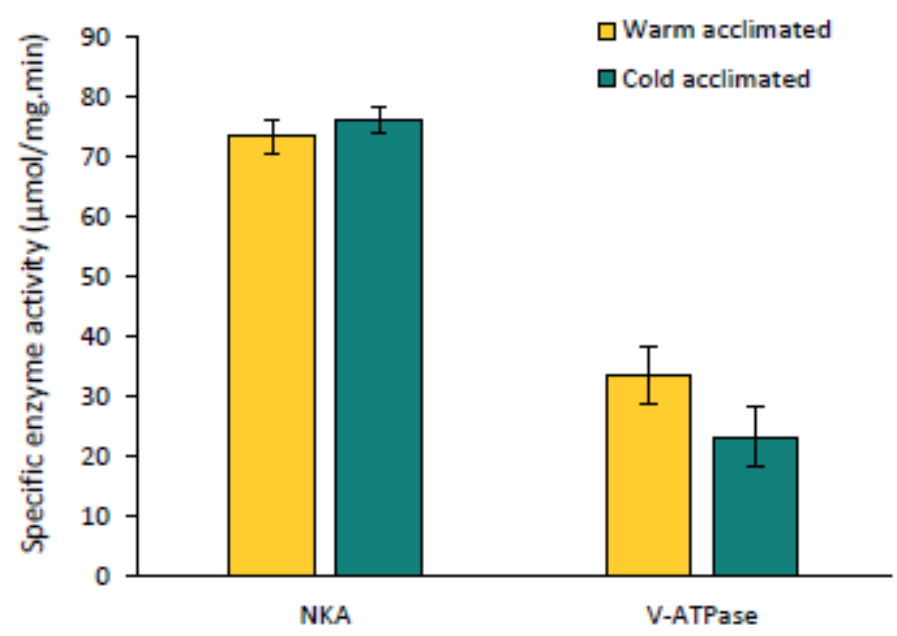

Figure 2 